\title{
Suboccipital craniotomy in the surgical treatment of Chiari I malformation
}

\author{
Yu-Cheng Chou • Rajashree Sarkar • \\ Ferdnand C. Osuagwu • Jorge A. Lazareff
}

Received: 4 May 2009/Published online: 4 June 2009

(C) The Author(s). 2009 This article is published with open access at Springerlink.com

\begin{abstract}
Object The object of this study was to present craniotomy for Chiari type I patients.

Materials and methods Six patients with Chiari type I underwent suboccipital craniotomy. All patients showed clinical improvement, and none had any complications. Two patients had syringomyelia; it disappeared in entirety. We describe the procedure for posterior fossa decompression.

Results Three-dimensional volumetric analysis using Vitrea workstation for postoperative posterior fossa volumes was calculated and was seen to have been increased on an average, from pre-operative $(168 \mathrm{cc})$ to postoperative volume (192 cc).

Conclusion We thus conclude that suboccipital craniotomy results in resolution of the Chiari symptoms yet achieves effective expansion of posterior fossa.
\end{abstract}

Keywords Chiari type I - Suboccipital craniotomy · Syringomyelia $\cdot$ Posterior fossa volume

\section{Background}

The surgical treatment for Chiari type I is one of the very few procedures in contemporary neurosurgery that does not contemplate replacing the bone flap. This is understandable

Y.-C. Chou $\cdot$ R. Sarkar · J. A. Lazareff $(\bowtie)$

Division of Neurosurgery,

David Geffen School of medicine at UCLA,

Los Angeles, CA, USA

e-mail: jlazareff@mednet.ucla.edu

F. C. Osuagwu

Division of Radiological Sciences,

David Geffen School of medicine at UCLA,

Los Angeles, CA, USA because the essence of the pathology is that the posterior fossa volume is inadequate for lodging the cerebellum. In our clinical experience, also corroborated by verbal exchange with our colleagues and also validated in the literature [7], numerous patients complain from headaches at incision site and an overall feeling of malaise following suboccipital craniectomy.

It is believed that adherence between muscle and dura, together with the development of occipital neuromas, is the source of postoperative complaint $[3,7]$. The literature for cerebellopontine angle tumor surgery has suggested that replacing the bone flap could improve the quality of life of the patients [5]. We have, in these lines, developed the following modification to the conventional craniectomy, respecting the need for posterior fossa expansion.

\section{Technical note and case illustration}

We performed suboccipital craniotomy on six patients with Chiari type I, of whom three were men and three women with average age of 12 years. Two had syringomyelia (Table 1).

Surgical procedure

After exposure of the squamous part of the occipital bone, we performed a small burr hole just below the nuchal line, 2.5 to $3 \mathrm{~cm}$ from the midline. From the burr hole, we proceeded either with a kerison or with a B2 footplate towards the contralateral side and then down to the foramen magnum. In this fashion, we created a rectangular craniotomy. The dura was incised in a "Y"-shaped manner and patched with dura guard over outer layer of synthetic dura matter substitute (Gortex). Leibinger plate was attached to 
Table 1 Clinical cases and their symptoms

\begin{tabular}{|c|c|c|c|c|}
\hline Age & Gender & Symptoms & $\begin{array}{l}\text { Preoperative } \\
\text { volume } \\
\text { (Vitrea; cc) }\end{array}$ & $\begin{array}{l}\text { Postoperative } \\
\text { volume } \\
\text { (Vitrea; cc) }\end{array}$ \\
\hline 17 & Female & $\begin{array}{l}\text { Headaches, left-sided } \\
\text { numbness (synrix) }\end{array}$ & 170 & 180 \\
\hline 18 & Male & Headache and vomiting & 187 & 198 \\
\hline 13 & Female & Sensory impairment & 172 & 203 \\
\hline 4 & Male & $\begin{array}{l}\text { Headache, neck pain, } \\
\text { and upper extremity } \\
\text { paresthesia (synrix) }\end{array}$ & 144 & 183 \\
\hline 14 & Male & Headaches & 155 & 177 \\
\hline 6 & female & Headaches and syncope & 181 & 197 \\
\hline
\end{tabular}

the inner table of the bone flap, and the other end of the plate was attached to the outer table of the skull with $2 \mathrm{~mm}$ screws, which allowed elevation of the bone flap (Fig. 1).

Measurement of posterior fossa volume

The calculation of posterior fossa was done by two methods. One method was automated measurement generated by the Vitrea workstation and the other by using the same principle used for calculating volume of arteriovenous malformation (AVM) from sagittal $\mathrm{T} 1$ magnetic resonance imaging (MRI) images [1].

The sagittal $\mathrm{T} 1$ preoperative and postoperative images were obtained and processed by Vitrea workstation (Vital Images), versions 3.7 (Dual Processor $850 \mathrm{MHz}-1 \mathrm{GHz}$

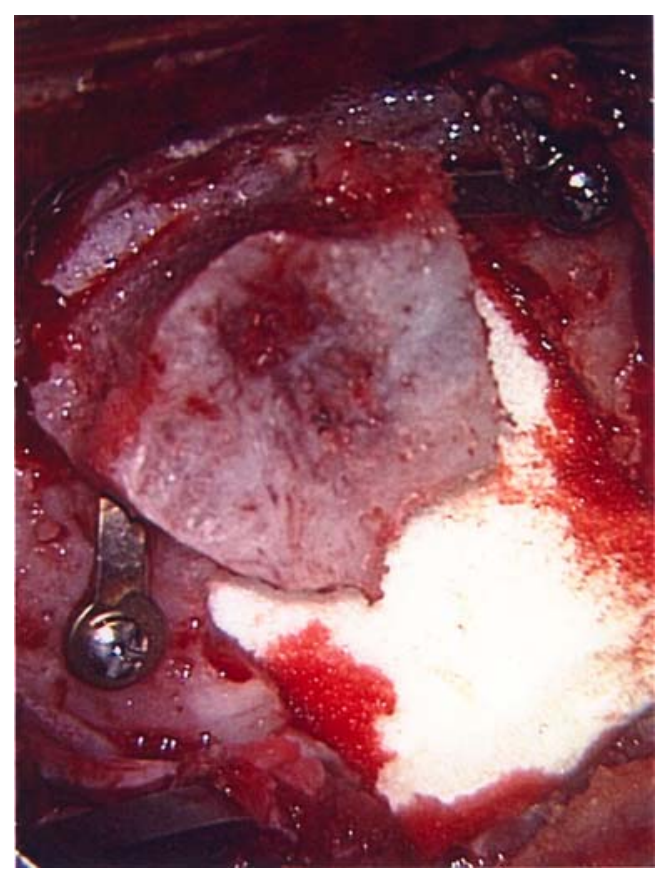

Fig. 1 Intraoperative photograph showing the elevation of the bone flap after attaching the Leibinger plate to the inner table of the flap
Pentium III) for 3-D quantitative interactive volumetric rendering using the free-sculpting tool. The sagittal contour of the posterior fossa was manually traced on each of the 4-mm thick slices to obtain a 3-D automated surface view of the posterior fossa. Automated measurements of the surface area (square centimeters) and volume (milliliters) of the posterior fossa were then digitally rendered. The posterior fossa was defined by both osseous and dural marginal anatomy, with the posterior border of the clivus and dorsum sellae as the anterior border, the line between the basion and opisthion as the caudal border, and the anterior margin of the occipital calvarium as the posterior border. A line extending between the poster superior margins of the dorsum sellae to the straight sinus extending posterior along the superior tentorial leaf to the level of the torcula was the superior border [2].

The principle of near ellipsoid shape and thereby calculating its volume from the MRI sagittal T1 image using the same formula as used for calculating volume of an AVM, i.e., $4 / 3($ pi $) \times$ lenght $/ 2 \times$ height $/ 2 \times$ width $/ 2$ was undertaken [1].

\section{Results}

Follow-up period was on an average 7 months. There has been no complication. There has been an improvement of the overall quality of life of our patients, and we have observed that, for those who had syringomyelia, this resolved in its entirety (Fig. 2). Post-operative headaches improved after a period of 3 to 4 weeks in all patients.

Three-dimensional analysis of posterior fossa volume using Vitrea workstation (vital images) demonstrated enlarged postoperative posterior fossa volumes $(192 \mathrm{cc})$ compared to preoperative volumes of $(168 \mathrm{cc})$ [2]. The average volume of posterior fossa, as calculated by the formula which was used to calculate the volume of arteriovenous malformation, is

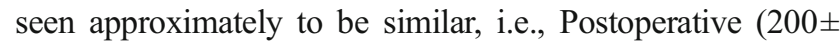
$7 \mathrm{cc})$ as compared to preoperative volume of $(170 \pm 5 \mathrm{cc})$. Our calculated posterior fossa volume was in comparison with volumes reported in the literature $[6,8]$.

\section{Discussion}

While surgeons agree that the posterior fossa volume needs to be expanded, we differ in the method by which we achieve it. We all are well aware of different techniques that range from massive craniectomy and durectomy without reconstruction of the latter to craniectomy alone or tonsillectomy without craniectomy.

Our results add another page to the conundrum of what is the best procedure for a symptomatic Chiari patient. It seems that craniotomy as described above allows a 
Fig. 2 Showing preoperative and postoperative scans, with resolution of the synrix
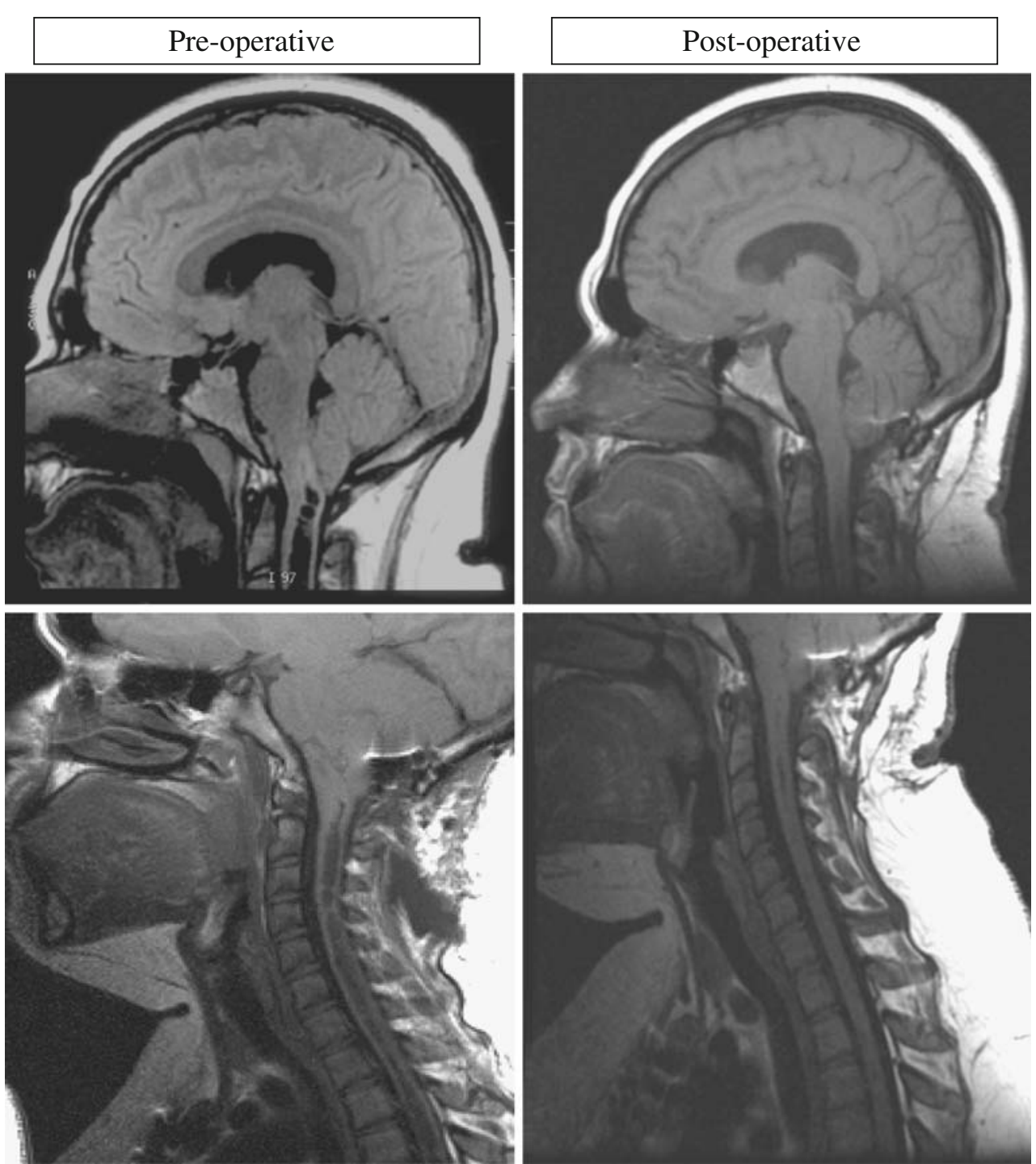

clinically relevant expansion of the posterior fossa volume, achieves decompression significantly, and also reduces the syringomyelia.

The added advantage for the patient of having a natural plane restored between the layers of muscle and dura or dura substitute should not be minimized. In the literature, the incidence of headache lasting beyond the initial postoperative period after craniectomy is $0 \%$ to $65 \%$ [4]. The dura of the posterior fossa is richly innervated with nerves and is rich in pain-sensitive receptors. Fibrous adhesion between nuchal musculature and the exposed dura generates a thick scar tissue and produces pain whenever there is neck motion due to traction. This adherence has also been demonstrated pathologically [5]. This explains why craniotomy is more physiological in preventing dural adhesions. Also, the role of dura guard or the dura substitute in improving the outcome postoperatively is important by absorbing the residual epicranial and epidural blood which is a potential irritant and inducer of intense inflammation of overlying subcuta- neous tissue and nuchal muscles. With regards to cranioplasty, it has been seen that the cranioplasty material itself could lead to local tissue reaction and edema and lead to postoperative headache [7].

With regards to expansion of the volume of the posterior fossa with craniotomy, the concept of near-ellipsoids should be introduced. We found almost the same measurements by calculating with the formula for an ellipse as with the volume calculated by 3-D volumetric analysis using Vitrea workstation. Therefore, we proceeded with these findings based on the principle from applied physics that the volume of the posterior fossa is dependent on the increment of the length of the major axis like the volume of near-ellipsoid structures. Meanwhile, there were not many changes in the other dimensions of minor axes of the height and the width as demonstrated by comparing the preoperative and postoperative MRI images. We thus infer that the increase in the volume of posterior fossa can be achieved even with replacing the bone back in a fashion that leads to increase in length. 


\section{Conclusion}

This short communication is thus to emphasize and enthuse us on better understanding of the mechanism of the disease process for Chiari type I malformation. With alleviation of clinical symptoms with suboccipital craniotomy, we wish to share with our colleagues this modest modification to the technique for treatment approach for Chiari type I malformation.

Open Access This article is distributed under the terms of the Creative Commons Attribution Noncommercial License which permits any noncommercial use, distribution, and reproduction in any medium, provided the original author(s) and source are credited.

\section{References}

1. Manchola IF, De Salles AA, Foo TK, Ackerman RH, Canadia GT, Kjellberg RN (1993) Arteriovenous malformation hemodynamics: a transcranial Doppler study. Neurosurg 33(4):556-562
2. Osuagwu FC, Lazareff JA, Rahman S, Bash S (2006) Chiari I anatomy after ventriculoperitoneal shunting: posterior fossa volumetric evaluation with MRI. Childs Nerv Syst 22(11):14511456

3. Santarius T, D'Sousa AR, Zeitoun HM, Cruickshank G, Morgan DW (2000) Audit of headache following resection of acoustic neuroma using three different techniques of suboccipital approach. Rev Laryngol Otol Rhinol (Bord) 121 (2):75-78

4. Schaller B, Baumann A (2003) Headache after removal of vestibular schwannoma via the retrosigmoid approach: a long-term follow-upstudy. Otolaryngol Head Neck Surg 128(3):387-395

5. Schessel DA, Nedzelski JM, Rowed D, Feghali JG (1992) Pain after surgery for acoustic neuroma. Otolaryngol Head Neck Surg 107(3):424-429

6. Sgouros S, Kountouri M, Natarajan K (2006) Posterior fossa volume in children with Chiari malformation Type I. J Neurosurg 105(2 Suppl):101-106

7. Silverman DA, Hughes GB, Kinney SE, Lee JH (2004) Technical modifications of suboccipital craniectomy for prevention of postoperative headache. Skull Base 14(2):77-84

8. Trigylidas T, Baronia B, Vassilyadi M, Ventureyra EC (2008) Posterior fossa dimension and volume estimates in pediatric patients with Chiari I malformations. Childs Nerv Syst 24 (3):329-336 